\title{
ELS INVENTARIS POST MORTEM I LA CULTURA DELS MERCADERS MEDIEVALS $^{1}$
}

\author{
Jaume Aurell i Cardona
}

L'estudi de la cultura, en les seves múltiples manifestacions, ha estat sempre un dels aspectes que més ha interessat als historiadors. La progressiva inter-connexió que s'ha dut a terme entre les diferents ciències socials (antropologia, filologia, història, filosofia) ha facilitat els avanços de la història de la cultura, ben palesos en un atent recorregut historiogràfic d'aquests últims temps. Tot $\mathrm{i}$ així, els estudis d'història cultural han sufert un canvi qualitatiu en aquests darrers anys, arrel de l'assimilació del corrent historiogràfic de la història de les mentalitats.

\section{LA DOCUMENTACIÓ NOTARIAL I LA HISTÒRIA DE LES MENTALITATS.}

La metodologia que tradicionalment s'havia emprat pels estudis específics de la història de la cultura no anaven més enllà d'una visió de les manifestacions artístiques i literàries més sobresortints de cada una de les èpoques històriques. L'enfocament positivista, que va escampar la seva influència en tots els ordres del saber, no era aliè a aquesta orienta$\mathrm{ci}^{2}$. Amb la arribada dels aires renovadors de la història de les mentalitats, el concepte de cultura, aplicat a les ciències humanes, ha esdevingut molt més profund $\mathrm{i}$ aplicable a la quotidiana realitat històrica. Els treballs

'Abreviatures emprades: AHPB, Arxiu Històric de Protocols de Barcelona; AHCB, Arxiu Historic de la Ciutat de Barcelona; APP, Arxiu de la Parròquia del Pi. Aquesta investigació ha estat duta a terme gràcies a una beca de la Generalitat de Catalunya.

${ }^{2}$ Aquesta generalització no pot fer oblidar algunes obres cabdals en la història de la cultura, elaborades al començament del segle, que han assentat els fonaments per a la revisió historiogràfica posterior: podem citar-ne dues de força penetrants, que ja han esdevingut clàssiques: Charles Homer Haskins, The Renaissance of the twelfth century, Cambridge (Mass.), $1927 \mathrm{i}$ Johan HuIzInGA, El otoño de la Edad Media, Madrid, 1985 (Leyden, 1927). 
de Georges Duby ${ }^{3}$, Michel Vovelle ${ }^{4}$ i Jacques Le Goff ${ }^{5}$ són alguns dels més representatius pel que fa a aquesta nova orientació.

Tota aquesta revolució historiogràfica no haguès arribat a una veritable transformació del concepte de cultura ni haguès assolit la suficient diversitat de la temàtica analitzada sense una correcta interpretació de les fonts notarials. Dins de la documentació notarial, han estat els testaments, inventaris i capítols matrimonials els que han atorgat la possibilitat al historiador de les mentalitats d'endinsar-se en el món de la cultura, en el seu concepte més ampli, col-lectiu i popular ${ }^{6}$.

D'entre la terna esmentada de les fonts més característiques de la documentació notarial aplicada a la història de les mentalitats, l'estudi del més enllà a través dels testaments és el que ha esclatat amb més força en aquests últims anys? ${ }^{7}$. Alguns estudis complementaris, basats en testimonis literaris, han vingut a completar aquesta anàlisi de la concepció de l'home pel que fa al més enlla, però fins i tot es veuen obligats a referències oportunes a la font dels testaments $\mathrm{s}^{8}$. Aquesta tasca historiogràfica de qualitat ha originat unes reflexions abundants sobre la mateixa font notarial dels testaments. Tanmateix, un estudi metodologic d'aquest abast encara manca dur-lo a terme - d'una manera sistemàtica - en inventaris i capítols matrimonials.

Per altre banda, el desenvolupament de la història de les mentalitats ha fet possible una metodologia per a l'estudi estadístic de les dades que es desprenen d'una correcta interpretació de la documentació notarial. Aquest tractament estadístic s'ha dut a terme especialment a través dels testaments ${ }^{9}$.

${ }^{3}$ Vid, per exemple, Georges Dusy, Los tres órdenes o lo imaginario del feudalismo. Barcelona, 1983 (1978).

${ }^{4}$ Vid. Michel Vovel.le, Pièté barroque et déchristianisation en Provence au Xvme siècle. Paris, 1971 i la seva exposició programàtica a Ideologías y mentalidades, Barcelona, 1985 (1982).

${ }^{5}$ En aquest sentit és força il-lustrador el seu recull d'articles Pour un autre moyen age. Temps, travail et cuiture en Occident, París, 1977.

${ }^{6} \mathrm{Amb}$ aquest terme no només fem referència als estudis de cultura popular pròpiament dits (vid. per exemple, Michael MULLET, Popular culture and popular protest in late medieval and early modern europe, Kent, 1987 - traducció a Critica, Barcelona, 1990-), sinó també a tots aquells que, prescindint d'una concepció elitista de la cultura - és a dir, la que se centra exclusivament en el camp de les seves manifestacions més espectaculars-, sap entrar en el món de la quotidianitat, de lesfera privada, dels valors i costums majoritàriament comuns a tota una societat.

${ }^{7}$ Bon exponent daquesta historia de la mort són les excel-lents monografies de Jacques Chifolene, La comptabilité de l'au-delà; les hommes, la mort et la religion dans la région d'Avignon a la fin du Moyen Âge, Palais Farnese, 1980, i de Michel Vovelie, La mort et l'Occident de 1300 à nos jours, París, 1983, que han estat acompanyades de tot un seguit d'estudis a nivell regional que seria impossible denumerar detalladament.

${ }^{8}$ És el cas de Jacques Le Gopr, El nacimiento del Purgatorio, Madrid, 1985 (París, 1981).

${ }^{9}$ Vid. l'estudi de M.T. Lorcin, Vivre et mourir en Lyomais à la fin du Moyen Áge, París, 1981 . pp. 18 i següents i Jacques BeAuror, aFamilles marchandes de Bishop's Lynn au XIve siècles al recull darticles Le Marchand au Moyen Age, Reims, 1992, pp. 175-187. Per al cas de la Barce- 
possiblement per la raó esmentada en el paràgraf anterior - la major atenció que se'ls hi ha donat fins ara a la historiografia de les mentalitats-. És facil adonar-se dels aventatges que es desprenen d'aquest tipus de tractament de les fonts notarials, des del punt de vista de la història de la cultura.

En el cas dels inventaris, encara no s'han dut a terme uns estudis en extensió com els què hem fet referència pels testaments, com tampoc una epistemologia de la pròpia font, ni un tractament essencialment estadístic. Tanmateix injust deixar de banda els fruits recollits ja per la dedicació de la historiografia del nostre país a l'estudi dels diferents aspectes que ens transmeten els inventaris ${ }^{10}$. Una carència encara més accentuada la trobem en el cas dels capítols matrimonials, però aquí ens restringirem a l'estudi metodològic de l'aplicació de la font notarial dels inventaris a una problemàtica historica concreta.

\section{ELS INVENTARIS POST MORTEM I LA HISTÒRIA DE LA CULTURA.}

Els inventaris s'han constituït en un bon instrument per l'anàlisi dels aspectes culturals més entroncats amb la història de les mentalitats, la vida privada i els costums socials més generalitzats. Aquest nou enfocament és inabastable si les fonts emprades es basen exclusivament en els testimonis més oficials que ens ha transmès, per exemple, la correspondència oficial, la documentació emanada de la pràctica política, l'aplicació de les lleis o la mateixa legislació. En aquest sentit, els inventaris tenen un caràcter de privacitat i d'espontaneitat que només trobem excepcionalment en la documentació emesa pel poder polític.

A desgrat de l'escassetat d'estudis pròpiament epistemològics referents als inventaris ${ }^{11}$, no es poca la tradició que hi ha a casa nostra de treballs basats en l'anàlisi dels inventaris post mortem. Al llarg d'aquest estudi farem referència a alguns d'aquests treballs, tot relacionant-los amb la problemàtica concreta que desenvoluparem.

En un altre lloc hem presentat l'estudi d'alguns aspectes de la mentalitat dels mercaders barcelonins a través de la informació que ens han

Iona baixmedieval, vegeu José-Ramón JULLÀ VISAMATA, „Las actitudes mentales de los barceloneses del primer tercio del siglo XIV», Amuario de Estudios Medievales, 20 (1990), pp. 15-51.

${ }^{10}$ Un bon recull d'aquests estudis es pot trobar a les referències bibliogràfiques de l'article de Flocel SABATER, aEls objectes de la vida quotidiana a les llars barcelonines al començament del segle XIvs, Anuario de Estudios Medievales, XX (1990), pp. 53-108.

"Com és logic, hi ha excepcions: vegeu els comentaris de Núria SALES, elnventaris post mortems, LA Avenc, 92 (1986), pp. 54-57. La historiografia italiana, tot i aixf, compta amb bons coneixedors d'aquesta font: vegeu, per exemple, la reflexió metodològica de Christian BEC, el libri dei Fiorentini (1413-1608). Ipotesi e proposte» publicada a D.A., II Rinascimiento, aspetti e problemi attuali, Florència, 1982, pp. 215-230. 
transmès els inventaris dels béns d'aquests comerciants de la Barcelona del segle $X v^{12}$. Ara pretenem fer una anàlisi de caire més metodològic, partint sempre d'aquestes coordenades -inventaris post mortem dels mercaders de la Barcelona del segle Xv-, pero intentant abstreure'n els trets més característics de la informació que es pot filtrar d'un estudi atent d'aquesta font notarial.

La justificació de l'estudi de la cultura d'un estament social entès en la seva dimensió col-lectiva té algunes motivacions interessants per a l'historiador. Ja hem esmentat que una correcta interpretació de la documentació notarial - tal com ha pretès fer la història de les mentalitatspot donar moltes llums a aspectes fins ara inèdits. Apliqueu aquestes noves dades a una col-lectivitat - amb els trets comuns que la caracteritzen- $i$ podreu obtenir noves llums per l'esbrinament d'algun problema historiogràfic de pes: en el cas de l'anomenada crisi baixmedieval de la Corona d'Aragó —en la que s'han esmerçat tants esforços-, les consideracions que s'han fet fins ara, sempre des d'una perspectiva socioeconòmica ${ }^{13}$, poden venir complementats amb un estudi acurat de la dimensió cultural d'alguns dels seus protagonistes. I sembla evident que Yestament mercantil va tenir un paper de primer ordre en l'expansí́ de la Catalunya baixmedieval i en el procés d'autonomia de les ciutats, concomitant a aquesta embranzida político-econòmica.

L'estudi de la cultura del mercader medieval té uns bons precedents historiogràfics pel que fa al cas italia ${ }^{14}$. Aquesta orientació, des d'un prisma essencialment culturalista, va tenir com a consequència posterior uns quants estudis monografics sobre la mentalitat del mercader italià, que sempre s'ha pres com el exemple paradigmatic ${ }^{15}$. Els estudis sobre els

\footnotetext{
${ }^{12}$ Jaume AURFLL, *Espai socila i entorn físic del mercader barcelonís Acta Mediaevalia, 13 (1992), pp. 253-273.

${ }_{13}$ Pensem sobretot en la discussió historiográfica encetada per Jaume Vicens Vives i Pierre Vilar, que ha tingut els seus fruits amb les documentades monografies de Claude CARRÉRE, Barcelona, 1380-1462, un centre econùmic en època de crisi, 2 vols., Barcelona, 1977 (París, 1967). Mario DeL. TRePPo, Els mercaders catalans il expansió de la Corona catalano-aragonesa, Barcelona, 1976 (Napols, 1972) i Carme BATLE, La crisis social y económica de Barcelona a mediados del siglo $x \mathrm{~V}$, Barcelona, 1973, a més de nombrosos articles referents a aspectes més específics. Una interessant reflexió historiogràfica sobre aquest tema la podeu trobar a J.E. Ruz DoméNECH, «La crisis catalana del siglo XV: ¿ zrealidad histórica o fieción hístoriografica?». Cuadernos de historia. Anexos del la revista Hispania, 8 (1977), pp. 71-117.

${ }_{14}$ Dos articles van ser decisius per anar-hi establint una metodologia: Henri PIRENNE, «'instruction des marchans au moyen age», Annales d'histoire économique et sociale, I (1929), pp. 13-28 i Armando SAFORI, \&La cultura del mercante medievale italiano» a Studi di Storia Economica (secoli XII, XIV, XV), Florència, 1955, vol. t, pp. 53-93.

${ }^{15}$ En aquest aspecte, cal destacar les monografies de Jacques LE GorF, Marchands et banquiers du Moyen Áge, París-la Haia, 1956, Christian BEC, Les marchands écrivains, affaires et hunanisme à Florence, 1375-1434, Paris, 1967, i Benjamin Z. KFDAR, Merchants in crisis. Ge novese and Venetian men of affairs and the Fourteen-Century Depression, Nova York, 1976.
} 
mercaders catalans, sempre han estat mediatitzats per aquesta dependència vers la historiografia dedicada a l'estudi dels mercaders italians. Aquest condicionament, junt amb el fet que ja hem esmentat de la orientació bàsicament socio-econòmica del paper dels mercaders en la societat catalana baix-medieval, poden haver fet obviar els aspectes més pròiament culturals que es desprenen d'un estudi acurat de la documentació notarial, i més concretament dels inventaris.

D'entre la documentació notarial, els inventaris són els que ens aporten una informació més objectiva, des del moment que la intenció del notari és la de fer un enregistrament fotogràfic dels objectes - mobles i immobles - que eren posseits pel difunt. El que cal esbrinar és quin grau d'exhaustivitat té aquest recull ${ }^{16}$. I, a més, ens transmeten també unes dades quantitatives, facilment interpretables per l'historiador des d'un punt de vista estadístic. Mirant així les coses, els inventaris són l'eina més útil per a endegar un estudi de la cultura en el seu sentit més ampli i profund: el conjunt de manifestacions que representen i defineixen els valors i les conviccions d'una col-lectivitat.

\section{LA CULTURA DELS MERCADERS I ELS INVENTARIS: UNA PROPOSTA METODOLÖGICA}

Per una primera hipòtesi respecte a una correcta interpretació metodològica dels inventaris, enumerarem a continuació aquells aspectes que ens han semblat més determinants cara a l'estudi de la cultura d'un grup social determinat. Aquesta enumeració no pretèn ser exhaustiva, per la senzilla raó de que es tracta de diferents trets característics que es desprenen de la informació que transmeten els inventaris des del vessant específicament cultural, amb les seves múltiples manifestacions. A més, ja hem esmentat que ens referirem al cas concret dels mercaders barcelonins baixmedievals, la qual cosa restringeix el nostre camp d'acció, però al mateix temps el fa més coherent.

Entre aquests aspectes, cal fer una distinció en primer lloc dels trets que fan referència a la vida privada i els que fan referència a la vida professional. Aquesta és, però, una distinció a posteriori: els inventaris no diferencien explícitament els objectes que s'ordenen a una $\mathrm{i}$ altre dimensió de la vida dels mercaders. En aquest sentit, era molt més gran encara la simbiosi vida privada-vida professional entre els mercaders que no posseïen

\footnotetext{
${ }^{16}$ A desgrat dels desequilibris de la riquesa de la vida material, detectable fins i tot en elements del mateix estament, no deixa de sorprendre algun fet aillat, com que en l'inventari del mercader Mare Seyol no hi aparegui cap llibre, enmig d'una riquesa material notable (vid. el seu inventari a AHPB, Simon CARNER, Tercius liber inventariorum, 1430-1438, f, 380r-387r, inventari del 2 de març de 1437),
} 
més que una habitatge a la ciutat, en el que combinaven la vida familiar a la llar amb el desenvolupament de la vida professional. En canvi n'hi ha d'altres que, potser pel major volum de la seva activitat comercial, tenien diferents albergs escampats per la ciutat ${ }^{17}$, a despit dels que tenien llogats.

D'aquesta primera distinció vida privada-vida professional, passem a una segona distinció que està directament relacionada amb la mentalitat del mercader: la seva formació intel-lectual i la seva religiositat. D'aquests dos aspectes també ens donen suficients indicis els inventaris, a través dels objectes més directament relacionats amb la cultura intel-lectual $i$ la vida religiosa. En la base de aquestes dues distincions cal fer referència a la cultura material, que es desprèn d'una primera anàlisi dels inventaris, i d'on brollaran les posteriors conclusions per als altres quatre aspectes que ja hem esmentat. Començarem, dones, per l'estudi metodológic de la cultura material. passant posteriorment als indicis que ens dóna la documentació sobre la vida privada i la professional, per acabar amb els trets més característics de la formació intel-lectual i la seva espiritualitat.

\section{LA CULTURA MATERIAL}

El primer que suggereix l'inventari és el nivell de vida, que es manifesta amb un determinat nombre i una especifica qualitat dels objectes enregistrats. Pel cas concret dels mercaders, ja podem treure una primera conclusió, que fa referència a la seva constitució com a estament: la gran diferència del grau de riquesa material que tenen els seus membres ${ }^{18}$. Això era comprensible en un estament com el dels mercaders, on la possibilitat d'arruinar-se era tal ${ }^{19}$, atès l'escàs desenvolupament de la legislació $i$ els mitjans per la defensa i la promoció de la inversió en tasques mercantils.

La cultura material ens aporta, doncs, una visió objectivada pel que fa al aspecte més quantitatiu de les possessions dels mercaders. En aquest

${ }^{17}$ Aquest és el cas del mercader barceloní Francese Girona, que té uns quants albergs dispersos per la ciutat (AHPB, Galceran BALAGUER, Pliego de inventarios, 1463-1510, inventari del 25 de novembre de 1438). En canvi, el mercader barceloni Guillem Pujol no sembla tenir cap habitatge a la ciutat, la qual cosa afavoriria la simbiosi vida privada-vida professional de què parlem al text (AHPB, Bartolomé Cosra, Pliego de inventarios, 1441-1450, ff. 132 r-163v, inventari del 2 d'abril de 1449 ).

${ }^{18} \mathrm{Per}$ citar-ne algun exemple, compareu la riquesa que es desprèn de l'inventari del mercader barceloni Mare Seyol (AHPB, Simon CARNER, Tercius liber inventariorum. 1430-1438, ff. 380r-387v, inventari del 2 de març de 1437) amb l'escassetat del mercader Jaume Soler (AHPB, Simon Carker, Secundus liber inventariorum et enconfun, 1415-1429, 88. 166r$167 \mathrm{v}$, inventari del 14 de novembre de 1420 ).

${ }^{19}$ És el cas del mercader barceloni Guillem Rabassa, del carrer del Carme, almoiner de la parroquia del $\mathrm{Pi}$, de qui es diu que és un pobre molt vergonyant (APP, Llibre de registre, 1432-1433, f. 29r). 
sentit, pensem que aquesta objectivitat és més pregona que la que poden donar les escasses fonts literàries que hem conservat respecte a la vida dels mercaders o la que ens comuniquen els valuosos manuals de mercaderia ${ }^{20}$, tot $\mathrm{i}$ que seria absurd menysprear aquests altres tipus més subjectius de fonts, de la que es poden treure dades complementàries, imprescindibles per fer-se una idea integradora de la cultura i la mentalitat del mercader.

En qualsevol cas, la história estadística és fonamental cara a l'anàlisi de les dades que ens transmeten els inventaris. És necessari ordenar i esquematitzar la informació, per treure-li tot el suc: d'aquesta manera, objectes que poden semblar irrellevants esdevenen un material essencial per l'historiador de les mentalitats, sobretot per els aspectes més directament relacionats amb la vida privada, a la que tot seguit farem referència.

Per endegar aquest estudi estadístic, cal fer una primera classificació dels tipus d'objectes enregistrats en els inventaris. La primera gran distinció és la d'objectes mobles-objectes immobles. Els objectes mobles els trobem directament esmentats en la documentació; els immobles solen aparèixer a través de cartes i títols que s'assenyalen en els inventaris ${ }^{21}$, excepció feta logicament del mateix immoble on es troben totes les pertinences que s'estan detallant, la situació del qual s'especifica al inici del document. Dins d'aquesta primera distinció, els títols nobiliaris - molt excepcionals en el cas dels mercaders - i les rendes - en forma sobretot de censals o violaris- es poden considerar com a béns immobles, també recollits a través de la descripció dels documents que es troben a casa del mercader inventariat ${ }^{22}$. En aquest sentit, l'historiador agraeix l'exhaustivitat dels notaris a l'hora de redactar el document, que fa possible l'anàlisi d'aquests béns immobles: de qualsevol document que es trobaven a la casa en resumien el seu contingut (per això una informació molt valuosa referent a la vida professional dels mercaders - a la qual ens referirem més endavant - és la gran quantitat de cartes públiques ressenyades a la segona part dels inventaris).

Dins dels béns immobles, doncs, es poden distingir entre els habitatges —amb una finalitat de vida privada o comercial-, les propietats rústiques

20 Vid., per exemple, Miguel Gual Camarena, El primer manual hispánico de merca. dería (siglo XIV). Barcelona, 1981, a més de les edicions sobre els quatre manuals de mercaderia italians que han arribat fins als nostres dies.

${ }^{21}$ Entre aquests béns immobles hi incloem habitatges, botigues $i$ camps. De molts d'ells en tenim notícia a través de cartes de venda pública. Per citar-ne un exemple, vegeu l'inventari del mercader barceloní Jaume Boteller a AHPB, Bartolomé CostA, Pliego de inventarios, 1441-1450, ff. 185r-202r, 26 d'agost de 1449, especialment la compra que va fer de diverses cases, especificada als ff. $192 \mathrm{v}-193 \mathrm{r}$.

${ }^{22}$ Un cas paradigmàtic en aquest sentit el podeu trobar a l'inventari del mercader barceloní Berenguer de Massanet, que ja va esmentar Claude Carrère en la seva monografia (AHPB, Joan FRANCH, major, Inventarium factum de bonis venerabili Berengarii Maçaneti quondam mercatoris, civis Barchinone, 1442, 30 d'agost de 1442): la quantitat de rendes que ha acumulat és aclaparadora. 
i els títols de les rendes posseides. Entre els béns mobles, hem distingit aquells que fan referència al confort familiar (amb un capítol tan il-lustratiu i clarificador com és l'ostentació); en segon lloc els que es poden assimilar a la vida professional del mercader; els que tenen una relació directa amb la cultura, la formació intel-lectual o el lleure i, en quart lloc, els que estan adreçats a l'exercici de la vida espiritual i religiosa del mercader. En definitiva els quatre aspectes a què hem fet referència més amunt: vida privada, vida professional, formació intel-lectual i vida religiosa.

Com ja hem dit al principi, i no està de més ara repetir-ho, aquestes classificacions són a posteriori, per tal de facilitar la tasca de l'historiador, que re-organitza la casa inventariada per filtrar-hi les dades que creu que són més d'interés: l'organització de la casa del mercader medieval no sabia res d'aquesta divisió tan esquemàtica. És cert que hi ha alguns espais amb una clara tendència funcional ${ }^{23}$, però la majoria dels objectes estan repartits amb una gran espontaneitat i desordre funcional. L'aclariment és interessant per no caure en un esquematisme excessiu, que reduiria massa la realitat al subjectivisme de l'historiador.

L'anàlisi de la cultura material a través dels inventaris esdevé, doncs, la base sobre la que bastir l'edifici de l'estudi de la cultura i la mentalitat dels mercaders. En aquest sentit, la cultura material és un aglutinador dels altres aspectes, que a continuació passem a detallar.

\section{LA VIDA PRIVADA}

Els últims estudis dedicats a la vida privada ${ }^{24}$ han posat de manifest la utilitat de la documentació notarial, especialment dels inventaris, que faciliten a l'investigador una visió quasi fotogràfica del que era l'interior de la llar.

El primer aspecte que es pot analitzar respecte a la vida privada dels subjectes inventariats es l'organització de l'espai intern. La mateixa estructura dels inventaris, organitzats en una distinció espacial segons les diferents cambres que es va trobant el notari en el seu recorregut, facilita l'estudi de la jerarquització funcional de l'espai domèstic. Només hi ha alguna excepció, que es dóna en el cas dels pocs inventaris en què ha prevalgut el criteri alfabètic per damunt de l'espacial ${ }^{25}$. Hem tingut la sort, dones, de que en la

${ }^{23}$ Ens referim, per exemple, al cas dels escriptoris (scriptoris, segons la documentació), que era com el sancta sanctorum de la vida professional del mercader, on trobem també la seva biblioteca. Perd també es pot pensas en els cellers (espai acumulatiu), les cambres dels esclaus, etc.

${ }^{24}$ Vid. Georges Duby i Philippe ArIEs, Historia de la vida privada, 5 vols., Madrid, 1988 (Paris, 1985), especialment el vol. 2. De la Europa feudal al Renacimiento.

${ }^{25}$ Un exemple d'aquests casos excepcionals el trobem a l'inventari del mereader barceloni Amau Salavert a AHPB, ANONIM, Inventario por onden alfabético de los bienes relictos del difinto Amaldo Salevert, 1436. 
gran majoria dels casos els béns inventariats han quedat consignats en el seu contexte original: dins de la cambra corresponent. A través d'un estudi estadístic es pot arribar a fer un quadre amb les diferents estances de la casa i la seva utilitat més directe, la qual cosa permetrà relacionar, amb una suficient fiabilitat, el factor espacial amb el factor funcional. Aquesta simbiosi és especialment interessant pel cas dels mercaders, on es poden classificar les cambres dedicades a la tasca professional, a la vida privada $i$ els espais ambivalents.

L'estudi interpretatiu de l'organització de l'espai intern també pot donar moltes llums a la mateixa jerarquització dels elements que constitueixen la família dels mercaders. De fet, les cambres més grans i espaioses - com és lògic -, quedaven reservades al mercader i la seva muller, que a més solien estar orientades al carrer, cercant l'entrada de la llum natural ${ }^{26}$. Tanmateix, les reservades als esclaus solien estar en llocs baixos i obscurs. En les habitacions dels fills, l'espai es solia aprofitar al màxim: de fet, hi ha una prevalença absoluta dels espais més pròpiament comuns (sobretot el menjador, la cuina i l'entrada).

Feta l'anàlisi del factor més pròpiament estructural de la casa del mercader, cal distribuir els objectes enregistrats segons la seva finalitat. Així, trobem aquells que estan més directament relacionats amb la vida quotidiana, com els mobles d'ús comú, els estris d'higiene personal, els llits, etc. En segon lloc, aquells que fan referència al vestuari dels mercaders i la seva familia $i$, per acabar, els que es poden catalogar dins d'un apartat que es podria anomenar d'ostentació.

Tot i haver-hi objectes posseits per la gran majoria dels mercaders, es interessant analitzar aquesta última categoria —els béns no estrictament necessaris - perquè precisament marca la diferència entre uns $i$ altres. L'estudi de l'ostentació pot ajudar, per exemple, a remarcar els trets més característics que se'n desprenen de l'anhel per un taranna de vida noble que mostren alguns mercaders ${ }^{27}$. A més, també pot ajudar a marcar la línia divisòria del que els mercaders consideraven com una necessitat $i$ el que tenien com a afegit, i fer una comparació amb altres estaments de la societat barcelonina baixmedieval.

La parcel-la més íntima de la vida privada del mercader (les relacions familiars, el tracte que es donava a la servitud, l'ordre de prioritats en la re-

${ }^{26} \mathrm{El}$ mercader barceloní Feliu d'Olm, per exemple, vivia en la ecambra majoro de la casa, i deixava la acambra prop de la dispensas per al servei (AHPB, Pere de FoLguERES, menor, Pliego de inventarios sueltos 1404.1430, inventari del 16 d'agost de 1429.

${ }^{27}$ Entrariem aquí en uns aspectes amb clares connotacions socials, que no ens correspon ara analitzar. De tota manera, ressenyem que els inventaris són un bon complement, en aquest sentit, dels capítols matrimonials, on es detecta clarament, sobretot al final de l'edat mitjana, el desig d'algunes famflies dels mercaders més benestants d'emparentar amb el patriciat urbà, que representava l'ideari i la forma de vida pròpiament noble en un context urbà. 
partició dels béns, la dotació de les filles, etc.) no està explicitada en els inventaris: cal recòrrer a altres fonts notarials, sobretot testaments i capitols matrimonials. De tota manera, és evident que els inventaris poden ser una eina complementària excepcional, atesa la seva dimensió objectivada, que permet refermar alguna conclusió ja intüda a través de les altres fonts notarials ${ }^{28}$.

De la dimensió privada de la vida del mercader es passa, sense solució de continuîtat, a la seva vida professional, atesa la simbiosi existent en aquests dos camps. Aquesta compenetració la trobem tant en el vessant espacial (sota un mateix sostre s'esdevenen sense confussió tasques professionals $\mathrm{i}$ vida privada) com en el mental (ja que no deuria ser massa difícil per al mercader passar d'una activitat a l'altre, la qual cosa tindria conseqüències directes, per exemple, en l'educació dels seus fills). Tot $i$ així, hi ha uns trets molt característics que es poden deduir de l'anàlisi dels inventaris pel que fa a la cultura professional del mercader.

\section{LA CULTURA PROFESSIONAL}

La dimensió professional de la vida del mercader també esta àmpliament representada en els objectes que s'enregistren als inventaris. A més, en aquest camp, podem treure conclusions fins i tot del tipus de l'orientació que donaven a la feina mercantil, com també dels mitjans que tenien al seu abast per assolir una bona educació com a mercaders, que en la gran majoria dels casos habien rebut a la llar paterna.

El que primer es pot deduir dels inventaris dels mercaders respecte a la feina comercial és que tenen uns espais dedicats eminentment al desenvolupament de la seva vida professional: els escriptoris i els cellers. Això és perfectament compatible amb el que hem afirmat de la simbiosi entre vida privada-vida professional, perquè els escriptoris serven en els seus prestatges molts llibres d'entreteniment, la qual cosa ens fa pensar que també feien servir aquest espai pel seu lleure. A més, als cellers és difícil distingir els objectes destinats exclusivarnent al comerç dels que emprava la familia, la qual cosa referma encara més la idea de l'osmosi vida privada-vida professional.

Els escriptoris i els cellers representen, respectivament, la feina organitzativa i la feina acumulativa del mercader. Analitzar els objectes dels escriptoris és potser el més interessant de la informació que es desprèn

${ }^{28}$ Per exemple, Ia profusió de vestits per a les dones dels mercaders que trobem en alguns inventaris d'aquestes pot ajudar a considerar el tracte de favor que rebien dels seus marits (vid. linventari de Francisca, dona del mercader barceloní Bernat Descamp a AHPB. Simon CARNER. Quartus liber inventariorum et encantum, 1438-1445, ff. 144r-146r, 26 dagost de 1440): però la prova definitiva no vindra fins que no tinguem una estadística fiable del paper de la dona en les relacions familiars, a traves dels testaments dels mercaders. 
dels inventaris dels mercaders: aquest espai és el centre neuràlgic de les decisions professionals, però també adquireix una transcendència molt gran pel que fa a les relacions familiars i a l'organització del lleure del merca$\operatorname{der}^{29}:$ el mercader s'hi deuria passar molt temps, sobretot a finals de l'edat mitjana, on la feina mercantil s'havia desenvolupat suficientment com perquè hi hagués més possibilitat de la delegació de la feina de tipus menys sedentària.

Del celler, per la seva banda, podem treure una informació molt més enganxada a l'activitat purament comercial. Tot i així, la seva situació prominent — solia ser a prop de l'entrada - ens fa pensar en que també es deuria fer servir sovint com a despensa familiar. A més, és un dels factors que ens ajuda a graduar el nivell de vida del mercader en quiestió: en alguns inventaris se'ns parla de botigues repartides per la ciutat ${ }^{30}$, que assimilaven aquesta funció dels cellers, el que pressuposava una bona capacitat económica.

Tanmateix, una informació molt valuosa que ens donen els inventaris respecte a la cultura professional dels mercaders és la seva concepció del negoci mercantil, que podem analitzar a través de tots aquells indicis de rendisme que trobem enregistrats (sempre a través de la citació directe dels documents que el mercader conservava). L'existència de camps ${ }^{31} \mathrm{i}$ de títols de rendes ${ }^{32}$ fan palesa aquesta inclinació del mercader baix-medieval, que té unes connotacions socioeconòmiques que no podem ara analitzar.

Però el que ens interessa en aquest cas és el que aquest fet representa vers la cultura professional i la manera d'enfocar els problemes del mercader medieval: és aquesta evolució cap a negocis rendistes un dels factors de la decadència comercial i econòmica de la Barcelona de la segona meitat del segle Xv? És més intensa aquesta inclinació que en segles anteriors? Quines motivaciones reals té: l'anhel d'un model de vida noble o la recerca de la se-

${ }^{29}$ En l'escriptori hi sol haver la biblioteca del mercader, una bona taula (en l'habitació que el mercader Guillem Pujol destina a la funció d'escriptori hi trobem una taula d'walbir gran qui servia per scriptori:-AHPB, Bartolomé Costa, major. Pliego de inventarios, 1441-1450, f. 146r. inventari del 2 d'abril de 1449-), els llibres de comptabilitat (el mercader Antoni de Nogueres té un uarmari ab algunes cartes e libres de comptes e altres papersw-AHPB, Simon CARNER, Se. cundus liber imventarionum et encantum, 1415-1429, f. 157r, inventari del 19 d'agost de 1420-) $i$ algunes caixes o cofres.

${ }^{36} \mathrm{El}$ mercader Antoni de Nogueres parla duna ebotiga que es devant lo portal majors (AHPB. Simon CARNER, Secundus liber inventariorum et encantum, 1415-1429, f. 157r, inventari del 19 d'agost de 1420). Bernat Riba, mercader barceloní, té diferents botigues disperses per la ciutat (AHPB, Simon CARNER, Quartum liber inventariorum et encantum, 1438-1445, ff. Ir-16v).

${ }^{31}$ El mereader barceloní Bernat Ponsgem té tres epeces de terra», l'una amb arbres, una altra amb oliveres i una altra amb vinyes (AHPB, Andrés MiR, Pliego de inventarios, 1466-1487, inventari del 1486, f, 12v, 13ri $13 \mathrm{v}$ respectivament). Feliu d'Olm té dos camps de vinyes (AHPB, Pere de Folgueres, Pliego de inventarios sueltos, 1404-1430, f. 8v).

${ }^{32}$ Els censals apareixen en quasi tots els inventaris de mercaders, normalmeat acumulats al final del document; el que cal estudiar és el seu volum de negoci, per fer una anàlisi comparativa basant-se en una estadistica fiable. Vid. n. 22. 
guretat comercial per la pèrdua de confiança? Són preguntes que un estudi acurat dels inventaris (des d'un tractament estadístic i d'evolució cronológica) pot ajudar en gran mesura a respondre. Com veiem, doncs, fins i tot els inventaris esdevenen una eina coherent i fiable com a complement per l'estudi de problemes socioeconòmics, que fins ara sempre han tingut com a base la documentació oficial o, si més no, la comercial.

L'estudi de la cultura professional del mercader ens mena naturalment a la seva formació intel-lectual i a la seva educació, però preferim estudiar aquests aspectes des d'un punt de vista més integrador (es a dir, recullint conjuntament totes les dades que estiguin directament relacionades amb la cultura i la formació intel-lectual del mercader, sigui des del punt de vista de la vida privada i del seu lleure com des del punt de vista estrictament professional).

\section{LA FORMACIÓ INTEL.LECTUAL}

La formació intel lectual del mercader és l'aspecte que s'enllaça més directament amb la seva cultura. Al menys, així s'ha vist tradicionalment. Els estudis de H. Pirenne i A. Sapori que ja hem esmentat anteriorment ${ }^{33}$, que van obrir una fecunda polèmjca historiogràfica, es basen sobretot en aquests tipus d'indicis, que a continuació detallarem. Tot i aixi, en aquest article hem partit d'un concepte de cultura molt més extens, entre altres coses perquè així ho permet la riquesa d'informació que es desprèn dels inventaris. La font d'informació bàsica per l'estudi de l'aspecte propiament intel-lectual de la cultura són les biblioteques recollides en els inventaris. En el cas dels mercaders, aquestes biblioteques solen aparéixer, en la gran majoria dels casos, entre els objectes que es detallen en l'habitació dedicada a escriptori.

L'anàlisi i interpretació de les biblioteques medievals compta amb bons precedents historiogràfics a l'extranger, normalment a base d'un correcte estroncament amb altres ciències humanes, com la filologia ${ }^{34}$. A casa nostra s'han fet uns estudis més descriptius, però que constitueixen una valuosa aportació pel que fa al fons documental buidat $\mathrm{i}$ unes primeres aportacions metodològiques ${ }^{35}$.

${ }^{33}$ Vid. n. 14.

${ }^{34}$ Ens referim sobretot als treballs de Christian BEC, Les livres des florentins (1413-J608), Florència, 1974, Henri Bresc, Livre et société en Sicile (1299-1499), Palerm, 1971 i, més recentment, Texcel Hent monografía de JN. Hus GARTh, Readers and books in Majorca, 1229-1550, 2 vols., París, 1991.

${ }^{35}$ Per a l'època i el tema que ens ocupa, vid. especialment Josep Maria MAdURELL i MARIMON, Manuscrits en català anteriors a la imprempta (1321-1474). Contribució al seu estudi, Barcelona, 1974, i Carme BATLLE, «Las bibliotecas de los ciudadanos de Barcelona en el siglo XV» a Livre et lecture en Espagne et en France sous l'Ancien Régime, París, 1981, pp. 15-34. 
Els llibres que aparèixen als inventaris dels mercaders medievals - i això és extensible als altres estaments - eren considerats com un objecte més, tot $\mathrm{i}$ que el seu extraordinari valor material afavoria una descripció més detallada per part del notari. Normalment, quan s'enregistra Yincipit i el clausit dels liibres, no hi apareix el títol. I, a l'inrevés, quan s'especifica el títol, no se'ns dóna notícia del començament ni del final del llibre. En altres casos, se'ns transmet una informació molt complerta, fins i tot del color de la cuberta i el tipus de materials amb que estan confeccionats, així com la forma de la lletra. L'idioma en què estan escrits es sol deduir de les frases literals de l'incipit $\mathrm{i}$ el clausit, o del mateix títol. Són totes aquestes circumstàncies les que fan que la correcta interpretació del contingut dels inventaris de les biblioteques passi a ser una preocupació de primer pla per l'historiador.

Un cop superats els problemes metodologics que aquesta informació representa, l'estudi de les biblioteques esdevé un dels factors clau per l'esbrinament de la cultura dels subjectes inventariats. A través de les biblioteques ens adonem de la seva religiositat, de les seves lectures d'entreteniment, de la cultura professional específica d'un determinat estament o grup social o fins i tot del seu interès per unes disciplines aparentment minoritaries, com és el cas de la filosofia ${ }^{36}$.

Ara bé, aquestes conclusions s'han de treure en el mare d'una veritable crítica metodològica, que porti a distingir - per exemple - entre els llibres heredats i els llibres adquirits; entre les lectures simplement reconegudes i les realment assimiladas; entre els llibres com objecte de veritable interès cultural o més aviat d'ostentació. Són aspectes que no escapen a una acurada interpretació metodologica. Així mateix, l'anàlisi de les biblioteques permet un estudi comparatiu posterior, que dugui a interpretar correctament l'equació afany de culnura-nivell de vida entre els diferents estaments que consituien la societat medieval. D'aquesta manera, a més, es pot fugir de les formes estereotipades en que s'ha volgut descriure la cultura medieval, molts cops reduïda a cenobis i claustres.

Els altres aspectes referents a la cultura intel-lectual poden sorgir a través de l'estudi d'alguns elements de l'inventari aparentment més marginals, però que poden donar-nos força thums: el número de taules que trobem fora dels menjadors - apart de la del escriptori-, el contingut dels llibres de comptabilitat - sempre en el cas dels mercaders - o els indicis del grau cultural dels altres elements de la familia ${ }^{37}$.

\footnotetext{
${ }^{36}$ Qvants empresaris d'avui en dia p̧oden ostentar una biblioteca com la del mercader barceloní Francese Girona, que compta amb obres d'un Aristòtil, d'un Plató, d'un Ramon Llull o d'un sant Gregori? En poden veure alguns exemples representatius a Jaume AUREL, Espai social..., pp. 270-272.

${ }^{37}$ Saben llegir les dones dels mercaders? Una progressiva assimilació de la dona en les tasques mercantils afavoriria la seva incorporació al món il lustrat, que fins aleshores havia quedat restringit als cercles femenins de les grans famílies nobles i patrícies: no té cap més expli-
} 


\section{LA SENSIBILITAT RELIGIOSA}

Per últim, els inventaris es converteixen en una bona font pel que podríem anomenar el camp de la religiositat privada. Aquesta orientació de l'espiritualitat personal seria molt difícil d'intuir sense les notícies que ens han transmès els inventaris. Un detall tan senzill com el fet que trobem imatges de la Mare de Déu en moltes de les habitacións dels mercaders reflecteix una realitat que va molt més enllà de la simple participació dels ciutadans en les celebracions litúrgiques.

Lestudi de la sensibilitat religiosa a través dels inventaris dels mercaders medievals ve determinada per l'existència de tres objectes: els oratoris, les taules i els llibres amb temàtica religiosa. Els oratoris no tenien perquè ocupar tota una habitació, però assenyalen un espai més gran que les taules o els retaules. Aquests últims solen ser d'una sola imatge ${ }^{38}$, per bé que els oratoris poden ser representacions de dos o tres personatges o escenes evangèliques ${ }^{39}$.

Pel que fa a les lectures amb una temàtica religiosa, són perfectament aplicables les consideracions que hem fet en el apartat de la formació intel-lectual. Tanmateix, un estudi estadístic que hem dut a terme respecte a la temàtica dels llibres posseits pels mercaders baix-medievals barcelonins demostra que una gran part dels llibres són obres religioses, la qual cosa demostra uns indicis clars de la seva preocupació per l'espiritual.

Les dades que podem recollir respecte a la religiositat del mercader estan directament relacionades amb la seva cultura: una major o menor vida espiritual pot influir directament en la seva concepció del negoci mercantil, la qual cosa tindrà una repercussió directa en les pràctiques comercials. En concret, no és pot eludir facilment el problema de la usura ${ }^{40}$, que es deuria presentar molt frequientment en la vida del mercader: es evident que la lectura de llibres directament relacionats amb l'espiritual presuposen, entre altres aspectes, una educació que no negligia els temes religiosos, també els

cació el fet que el mercader barceloní Francesc Despuig hagi confiat a la seva dona la direcció dels seus afers durant el seu viatge a ultramar, tal com ho constata amb agraiment al seu testament (AHPB, Arnau LLEDO, Manual de testamenis, 1398-1404, testament del 8 de juny de 1404. f. $36 \mathrm{v})$.

${ }^{38}$ En l'inventari de la dona del mercader barceloni Joan Bori se'ns descriu «I retaula de drap en que és pintada la Salutació ab Sant Miquels (AHPB. Simon Carner, Quartus liber inventariorum et encantum, 1438-1445s, f. 232r.

${ }^{39}$ A casa del mercader Lluís Claramunt trobem al oratori en que es pintada la creu de Jesucrist e la Verja Maria e Sant Johan e d'altre ab daltres pintureso i al altre oratori en que es pintada la image de la Verja Maria e la Maria Magdalenas (AHPB, Simon CARNER, Tercius liber inventariorum, 1430-1438, f. 159v), que ens transmet la idea que no eren representacions senzilles.

${ }^{40}$ Per a una introducció als conceptes bàsics d'aquesta quiestio, vegeu Josep HERNANDO, «EI problema del crèdit i la moral a Catalunya (segle xIv) $w$, Acta Mediaevalia, annex t (1983), pp. 113-136. 
relacionats amb la moral mercantil. La conjunció de tots dos camps (intel-lecció $\mathrm{i}$ acció) donaria com a resultat una religiositat realment coherent, de la que podriem partir per aproximar-nos a l'explicació del problema tan debatut de la usura i la seva transcendència real en la vida del mercader.

L'estudi de la religiositat a través dels inventaris esdevé, doncs, una bona font no només per les conclusions pròpiament restringides a aquest camp, sinó també per endinsar-se en les conseqüències que es desprenen d'una mentalitat religiosa determinada en el camp social i professional.

Per mitjà d'un enfocament de la documentació notarial ben orientat metodològicament, fent especial esment en els aspectes de mentalitat i culturals, es transcendeix a reflexions en problemes que tradicionalment la historiografia ha fet exclusius a unes fonts de caire més oficial o simplement econòmiques.

Alguns dels aspectes que hem apuntat, tots relacionats amb la cultura material $\mathrm{i}$ les conviccions mentals, poden aportar dades complementàries als temes que ja s'han interpretat des d'un prisma bàsicament socio-econòmic. Aquestes consideracions, basades en la font dels inventaris post mortem, són aplicables analogicament a altres fonts de la documentació notarial, com els testaments i els capítols matrimonials, a base d'una comparació d'analogia. Tanmateix, aquesta comparació perd la seva identitat quan es duu a terme respecte a altres tipus de documentació, com per exemple la correspondència oficial, que està determinada per uns motllos molt més rígids que li fan guanyar amb objectivitat però que li fan perdre el taranna íntim i personal de testaments i inventaris. La documentació notarial té un caràcter d'espontaneitat i de privacitat que no és comparable a cap altre tipus de font.

Hem volgut fer aquest recorregut pels cinc aspectes esmentats partint sempre d'una investigació específica: l'estudi de la cultura dels mercaders baix-medievals barcelonins a través dels inventaris post mortem. Aquesta orientació permet afrontar amb unes premises més fiables qualsevol intent de re-situació metodológica, que esdevé més rigurós si esta fonamentat en l'anàlisi d'una problemàtica històrica concreta. Així mateix, l'estament dels mercaders barcelonins té una suficient maduresa com a grup social en el llindar de l'edat moderna com per ser susceptible d'un estudi monogràfic.

Els inventaris post mortem, al capdavall, són uns testimonis excepcionals dels trets culturals més objectivats que la riquíssima documentació baixmedieval aporta a l'historiador. La correcta aplicació metodològica d'aquesta documentació permet assolir dades força transcendents, sobretot des del punt de vista de la història de la cultura i de les mentalitats, que encara no estan del tot consolidades com a corrents historiogràfiques a casa nostra. 